\title{
"Juan Darién” de Horacio Quiroga. Los límites de la especie y alianzas biopolíticas
}

\author{
Horacio Quiroga’s “Juan Darién”. \\ The Limits of the Species and Biopolitical Alliance
}

\author{
NICOLÁS ROMÁN GONZÁLEZa \\ ${ }^{a}$ Universidad Andrés Bello, Facultad de Educación y Ciencias Sociales. Chile. \\ Correo electrónico: nicolas.roman@unab.cl
}

El siguiente análisis del cuento de Horacio Quiroga "Juan Darién" propone al animal como una categoría significativa dentro del campo literario latinoamericano. El argumento del relato basado en la transformación humano-animal en la selva muestra cómo la adopción de un tigre huérfano por una madre en el inicio del relato tiene negativas consecuencias tales como la persecución de lo animal dentro de lo social a lo largo de la diégesis. Esta trama se debate según las discusiones de la biopolítica (Foucault), el enemigo interno (Torrano) y la figuración del pueblo y lo animal. Esta adopción cuestiona los límites de lo humano, la naturaleza, la cultura y el uso del lenguaje. La provocación animal despliega diversos mecanismos de persecución biopolítica: el archivo en su relación al poder, el poder soberano y la condición de enemigo interno.

Palabras claves: animal, especie, metáfora, Horacio Quiroga.

This analysis of Juan Darién written by Horacio Quiroga proposes the category of animal as a significant element inside of the Latin American Literature. The plot of this story is about the adoption of an orphan tiger by a single mother. This plot is analysed according to the biopolitic (Foucault), the internal enemy (Torrano) and the people figuration and the animal. This action generates negative consequences, like the persecution of the animal. This adoption criticques the limits of humanity, nature, culture, and language. The animal biopolitical persecution deploys a diverse range of mechanisms, the archive and his relation to power, sovereign power and the internal enemy condition.

Key words: Animal, Species, Metaphorical Order, Horacio Quiroga. 
Quien prácticamente no es humano [y] vive en la selva [...] es un salvaje” (del latín "silva" proviene el italiano "selvaggio", del francés "sauvage", el español "salvaje", el inglés "savage")

Todo Caliban

Roberto Fernández

Retamar

La reivindicación de la animalidad como muestra de la naturaleza más intrínseca se rompe con la prohibición fundamental que desde siempre nos gobierna. Contra el desdoblamiento del dispositivo de la persona, el animal presente en el hombre, en todo hombre y en todos los hombres, viene a significar la multiplicidad, la pluralidad, la metamorfosis.

\section{Comunidad, inmunidad y biopolitica \\ Roberto Espósito}

Este trabajo describe cómo la transformación de un animal de la selva en un niño activa los dispositivos biopolíticos de persecución y aseguramiento de la frontera de la especie humana y el animal en el cuento "Juan Darién" del escritor uruguayo Horacio Quiroga. Este devenir animal activa los flujos de la transformación y el traspaso de una especie a otra. La metamorfosis activa el castigo, la tortura y el poder pastoral en una persecución del enemigo interno con el objetivo de eliminar al personaje para restablecer los límites de las especies.

El protagonista de este relato, publicado en El desierto (1924), es un pequeño tigre que adquiere la forma de un niño al ser adoptado por una mujer en un pueblo en la selva. La mujer viuda, afectada por la reciente pérdida de su hijo, encuentra a un cachorro de tigre cerca de su casa, lo adopta, lo amamanta y arrulla. El felino y la mujer viven juntos en el aislamiento selvático, aunque no sin temor debido a que "si se llegaba a saber en el pueblo que ella amamantaba a un ser salvaje, matarían con seguridad a la pequeña fiera” (248). La adopción tiene un giro cuando la mujer, ante la presencia de un hombre cerca de su casa decide, sobrecogida por el temor, esconder a la cría. Ella se siente intimidada y nerviosa frente a la presencia del extraño y sale de su hogar, sin embargo, fuera de la casa la mujer se encuentra con una serpiente. El reptil le concede el deseo de transfigurar al felino en un nińo, pero había una sola manera de romper este pacto humano animal advierte la serpiente, esto pasaría cuando una madre "entre los hombres lo[s] acuse" (182), esta acusación rompería su alianza y la transformación del animal en humano se acabaría irremediablemente.

Este animal ingresa en la sociedad del hombre amenazado por los discursos de captura de la retórica decimonónica, donde el animal juega un rol asociado con lo salvaje y la barbarie, opuesto a los códigos de la civilización y los ideales de la nación y el Estado. Los 
efectos de la alteridad animal dentro del cuerpo social -con su presencia extrańa- promueven la eliminación del enemigo interno, vuelto animal político, contrario a los principios de la soberanía. El animal depredador escindido de su manada, y fuera de su entorno natural, amedrenta a la especie humana como su presa y con esta violencia amenaza el fundamento de la vida en sociedad.

\section{LA MUERTE, LO HUMANO Y LO ANIMAL}

Nuestra lectura se basa en el poder pastoral (Michel Foucault) que considera a la población como un rebaño, el orden de estos argumentos está en el campo de la biopolítica. Un tigre, aunque tenga la apariencia de un niño, es una amenaza para la población y su gobierno pastoral. Ese humano-animal que es Juan Darién es un enemigo interno. El traspaso de las fronteras de la especie saca lo animal que hay en lo humano. El enemigo interno es leído según las ontologías de la monstruosidad de Andrea Torrano quien hace una lectura cruzada entre Thomas Hobbes y Giorgio Agamben para reflexionar sobre las implicancias de la metamorfosis humano-animal.

Los estudios críticos de la obra de Horacio Quiroga, cuyo espacio es la selva, han propuesto las confrontaciones entre lo humano y la naturaleza con distintos énfasis, nos situamos en este contexto por la relación entre lo humano y animal de nuestra perspectiva. Para iniciar esta discusión es importante seguir lo que señala Matías Ayala sobre las metamorfosis corporales, "la alteración entre las fronteras de las especies y los cuerpos remite a la vida como la apertura entre el cuerpo, el espacio y el sentido" (36). La cita del crítico sirve como base para analizar las transformaciones del cuerpo, como es en el caso de Juan Darién y, asimismo, para leer las transformaciones de los espacios, la selva y la frontera, y el sentido, la vida y la muerte, como ocurre en la producción de Quiroga.

La muerte y la naturaleza será señalada como una de las entradas de la obra quiroguiana según Noé Jitrik en los ańos setenta. Naturaleza y muerte son abordadas también por la crítica Gina Villamizar (2020), ella reconoce una muerte simbólica del mundo rural asociada con la naturaleza y los oficios tradicionales en los cuentos de Quiroga frente a la modernidad ${ }^{1}$. Los personajes son víctimas de accidentes asociados con la desarticulación de su modus vivendi de acuerdo con la imposición "del proyecto programado desde la ciudad y su consecuencia nociva para la supervivencia en la selva" (432). La autora destaca está confrontación entre el mundo rural y su explotación por la modernidad orquestada por los planes de la ciudad. Los oficios de jornaleros solitarios se oponen a los planes de explotación de los recursos de la selva según la autora, por ese motivo, la prosa de Quiroga está en una constante asociación con la muerte y la erradicación de la naturaleza con la avanzada capitalista.

\footnotetext{
${ }^{1}$ Estos son los cuentos analizados por Gina Villamizar: "A la deriva" (1912), "El regreso de Anaconda" (1925), "El hombre muerto" (1920), y "La cámara oscura" (1920).
} 
El tema de la muerte y la naturaleza es un eje de la crítica, como hemos destacado anteriormente, y las propuestas sobre este tema han establecido ese binomio en una relación fronteriza y liminar. José Duarte profundiza esa relación en su artículo "Horacio Quiroga como escritor de frontera", el autor examina las relaciones fronterizas del autor de Cuentos de la selva y añade más dicotomías para caracterizar esta producción narrativa "como pueden ser el tema de la barbarie y civilización, por su doble nacionalidad o por la conjunción de países que se tienen cerca de Misiones [...] Quiroga no se limita al tema de la muerte y la locura como muchos críticos han llegado a encasillarlo" (116), sin embargo, el tema de la muerte es una constante en la crítica, incluso, considerado como una clave sobre los límites de la vida y el sentido. La muerte en la obra de Quiroga, en distintos cuentos misioneros, es considerada como un campo de exploración, por este motivo, lo humano y lo animal es otro límite que traspasa el autor en la trama de "Juan Darién".

Una lectura sobre lo fatal relacionada con la exploración de los límites es defendida en el artículo "Horacio Quiroga, a Writer of the Limits" de Carlos Abreu, quien propone el problema de la muerte y su conceptualización como un tratado sobre la resistencia a la trascendencia, de este modo en la obra de Quiroga: "Nature is not divine, it is just nature; man is not permanent, nor sublime" (305). La desublimación de la naturaleza propuesta por Abreu realza la dimensión material y la finitud de los personajes, como señalamos junto con Matías Ayala más arriba, la muerte implica una reflexión sobre el sentido, sobre las interrogantes inmanentes en el ámbito de la naturaleza en una discusión sobre lo material y lo corporal, campo de estudios de nuestro trabajo.

La muerte para Carlos Abreu se presenta como límite y horizonte de clausura de la narrativa y del imaginario quiroguiano, el crítico señala: "the doomed characters encounter an ungraspable end, perishing in the limits of this world and ignoring what lies on the other side" (305). La muerte es el límite de la experiencia, una condición concreta e inmanente donde los personajes encuentran su finitud y la pertenencia al entorno material. Los personajes son marcados por lo fatal, "they perish in nature and they do not go beyond nature" (307). Muerte y naturaleza son establecidos como un límite inmanente a la experiencia, no hay trascendencia ni tampoco un elemento trascendental, divino o metafísico, aunque en "Juan Darién", el protagonista luego de la tortura vuelve a su cuerpo animal para vengarse de los humanos y enfrentar la colonización agresiva de los espacios rurales de la que fue víctima.

Las transformaciones del mundo de la naturaleza y la cultura, en el caso de "Juan Darién", proponen una relación compleja entre lo humano y lo animal y exploran el otro lado del límite de lo humano. La metamorfosis cruza las especies y la trama muestra un mundo de proximidad ajeno a las disposiciones de segmentación establecidas por el poder pastoral. El intercambio entre lo humano y lo animal cuestiona la separación de estas dos esferas, el estudio de este cuento hecho por Bridgette Gunnels, destaca el cruce de estos límites, "Juan Darién', effectively shows us that these boundaries are not as clear cut as they would seem. Metaphorically speaking, Juan Darién shows us complexity and hybridity are perhaps more accurate portraits of the natural and cultural worlds" (Gunnels 358). La 
representación del cruce de los límites de la especie en "Juan Darién" muestra la complejidad y la porosidad de esa frontera entre los cuerpos.

La condición de vecindad e hibridación, la alianza entre el mundo animal y humano es una protesta contra el poder pastoral. La metamorfosis es expuesta por otros autores como un punto crítico de la narrativa de Quiroga. Gunnels, Andermann y Gonçalvez, exponen cómo la metamorfosis explora el cuerpo y la naturaleza en otra dirección, hacia la transformación y la indeterminación de la condición humano-animal de Juan Darién.

\section{LA METAMORFOSIS Y PODER PASTORAL}

La presencia de la metamorfosis en los bordes de la civilización capitalista induce los deslindes de la especie y traspasa la barrera de las identidades excluyentes. Jens Andermann propone un análisis que está basado en la frontera como contacto, lee el espacio del relato y las acciones del protagonista sobre la base de la metamorfosis y la transformación, el crítico señala que "el relato de metamorfosis inscribe y forja un ambiente, una zona de frontera, que no es otra que la del capitalismo que avanza sobre sus bordes 'premodernos', silvestres y rurales" (2). El ambiente de la metamorfosis es el espacio de "Juan Darién", su trama es una lección sobre la vecindad y la frontera como se señala en el inicio del relato "Aquí se cuenta la historia de un tigre que se crió y educó entre los hombres, y que se llamaba Juan Darién. Asistió cuatro años a la escuela vestido de pantalón y camisa" (Quiroga 181). El narrador enfatiza el estatuto de la transformación y la ambigüedad del personaje: viste de pantalón y asiste a la escuela, pero es un tigre de la selva.

El pequeño niño Juan Darién con su alma de tigre es criado entre los humanos hasta que su escuela recibe una visita administrativa. El funcionario del Estado debe inspeccionar las aulas y los estudiantes para asegurar el avance de lo urbano sobre lo rural para imponer la soberanía del Estado en los márgenes de la civilización, por ende, tenemos una acción asociado con el poder pastoral. Ricardo José Gonçalvez Duarte, destaca que esta misión tiene el objetivo de delimitar la frontera entre la naturaleza y la cultura, en este caso, para mantener la diferencia excluyente entre humanos y los animales:

O homem, deslocado da cidade, encontra uma posição muito bem estabelecida no campo em uma relação hierárquica e rígida com os outros existentes daquela região, como os animais. Seja como aquele que encontra a paz na floresta, ou aquele que encontra nela monstros prontos para lhe devorar, tudo parece estritamente fixado (Gonçalvez 353).

En esta visita administrativa, la filiación animal de Juan Darién es descubierta. La inspección, la confesión y la imposición de una identidad humana entran en contacto en la sala de clases en el momento de cuestionar la especie del nińo que desajusta los límites de lo humano y lo animal. 
La diferencia de Juan Darién es percibida por el funcionario del Estado en una inspección de rutina. Posteriormente a su visita, el inspector manifiesta sus sospechas al concluir que, según el examen de la apariencia del muchacho, este no pertenecía a la especie humana. El funcionario ausculta la identidad corporal de Juan Darién y manifiesta su disconformidad con la apariencia del nińo-felino. El espacio pedagógico es presentado como un ambiente contaminado por la presencia de este muchacho. La mirada inquisitiva del inspector manifiesta la duda sobre la identidad, "Es extraño, muy extraño... murmuró el inspector" (183), la mirada del inspector reconocer el reflejo verde de la selva en la mirada del niño felino.

Esta sospecha no puede terminar hasta que del cuerpo del nińo emerja el animal, el inspector insta a hablar a Juan Darién, le pregunta por la naturaleza, lo mira y lo escucha, mientras las intervenciones infantiles son traspasadas por el sonido animal; ${ }^{2}$ este inspector, "Guardián de la máquina antropológica, [...] detecta en el trabalenguas la presencia de un cuerpo extrańo, un cuerpo de fábula, una traba que interrumpe el mecanismo de la lección que por supuesto no es otra que la lección de la especie" (Andermann 7). El vicario de la misión estatal en la selva está destinado a identificar las anomalías al interior de un sistema intolerante ante la diferencia, "Invadir a floresta, espaço limítrofe do vilarejo, e exterminar as feras que causam tanto horror aos seus habitantes, configura-se numa tentativa de ampliar a dominaçáo antropocêntrica" (Gonçalvez 357). El Estado promueve las identidades excluyentes de lo humano y lo animal en esta zona donde la escuela funciona como punta de lanza de la avanzada estatal, tanto Gonçalvez como Andermann destacan la encrucijada sobre la especie y su confrontación con el antropocentrismo. La frontera que cruza Juan Darién debe ser reestablecida por la máquina antropogénica.

A estas perspectivas podemos agregar que la escuela es uno de los elementos de un sistema que articula la función homogeneizante del poder pastoral en una perspectiva biopolítica. La vigilancia, como señala Michel Foucault, es "una benevolencia individualizada [cuyo ejemplo es] el pastor [que] vela para que todas sus ovejas, sin excepción sean recuperadas y salvadas" ("Omnes" 120). El inspector es el guardián de la identidad humana, promueve el cuidado de las ovejas del rebaño estatal y procura la expulsión del felino en medio de la grey. Asimismo, la finalidad de la escolarización es multiplicar y repetir la identidad social, cultural y política que construye la ciudadanía, por esto, ante la duda sobre la identidad felina de Juan Darién -el tigre en su interior es un depredador de humanos- no se debe vacilar, la preservación de la identidad se hace a fuerza de expulsar la diferencia y preservar el rebaño. La lección de la especie como la llama Andermann es una ejecución de este dilema pastoral del cuidado de la grey y la persecución de los predadores.

Las sospechas del funcionario sobre Juan Darién son suficientes para condenarlo a ser víctima de la violencia soberana. Esta acción está basada en la observación fehaciente de que el niño "Es una fiera del bosque, posiblemente un tigre" [por lo tanto] debemos matarlo,

\footnotetext{
2 "Juan Darién era el alumno más aventajado; pero con la emoción del caso, tartamudeó y la lengua se le trabó
} con un sonido extraño" (183). 
porque si no, él, tarde o temprano, nos matará a todos" (185). La sospecha y el mandato de la uniformidad obliga a los funcionarios a perseguir y eliminar al niño por su identidad ambigua, el delito es el vínculo con lo salvaje. Según una la lectura del poder pastoral esta ambigüedad impide la convivencia social porque "todos los hombres que viven muy cerca de la selva, odiaba[n] ciegamente a los tigres" (185). El funcionario gubernamental, orientado por su suspicacia, orquesta un plan para proponer a los habitantes del pueblo que el niño tigre debe ser expulsado y eliminado.

Una vez expuesta la sospecha se desencadena una persecución feroz, el mandato de la uniformidad y la vigilancia del poder pastoral se materializa en la definición de quiénes deben ser incluidos dentro del cuerpo social y sus instituciones, quienes deben ser rechazados y perseguidos, aunque existe una dificultad según el inspector para eliminar a Juan Darién, "no podemos hacerlo mientras tenga forma humana, porque no podremos probar ante todos que es un tigre" (185). A pesar de su apariencia, el niño se vuelve un problema y una anomalía, su condición animal debe ser expuesta, ya que esta es una alteridad de la identidad humana, una alteridad que descompone la definición de la especie humana. Su transformación corporal, su metamorfosis "mantiene con el discurso de la especie [la] subversión y resistencia" (Andermann 5), este es un cuerpo extraño que no es idéntico a sí mismo, humano y animal, en un contexto espacial al límite entre la naturaleza y la cultura.

La discordancia respecto de la constitución del cuerpo del niño felino es confirmada por medio de la tortura, paradójico método de salvajismo en medio de la civilización, Bridgette Gunnels menciona esta pérdida de la razón por parte de los habitantes del pueblo como un cruce, híbrido, entre la razón y la irracionalidad. El funcionario acuerda recluir al niño en una jaula y con el domador de fieras probarán que Juan Darién es un tigre. El suplicio aplicado al niño hace que salgan las rayas de su cuerpo prisionero, enjaulado, su castigo muta la naturaleza de ese cuerpo indefenso. El pueblo vociferante, sumado a la tarea del funcionario, consigue sus perversos objetivos, el niño felino grita y "sus gemidos adquirían un timbre profundo y ronco; y que su cuerpo cambiaba poco a poco de forma. Y la muchedumbre, con un grito salvaje de triunfo, pudo ver surgir por fin, bajo la piel del hombre, las rayas negras, paralelas y fatales del tigre" (188). Juan Darién es un tigre, una fiera de la naturaleza. La escuela, el pueblo y el inspector, todos ellos, funcionan como mecanismos de persecución a fuerza de excluir a Juan Darién.

La animalización forzada de Juan Darién por medio de la tortura instala la lección de la especie y establece a fuego las diferencias del antropocentrismo frente a las esferas interconectadas de lo natural, lo humano y lo animal. La aldea rechaza a Juan Darién por medio de la tortura y su espectáculo. La marca del latigazo de donde emergen las rayas negras del tigre se opone al regazo materno, es la escritura sobre el cuerpo que evoca el método punitivo de la colonia penitencia kafkiana, "Nuestra sentencia no es aparentemente severa. Consiste en escribir sobre el cuerpo del condenado" (Kafka 5). Esa lección del poder pastoral es la versión del Estado sobre una manera de inscribir los cuerpos y separar las especies, excluir lo natural de lo cultural, lo humano de lo animal. 
La objetivación de lo animal-natural ante la subjetivación de lo humano-cultural, expone una división hecha con la violencia del domador de fieras ejercida en la plaza pública: los latigazos. Así, esta visualidad morbosa coordinada por la masa enfebrecida impone una identidad subjetiva y filiativa, se confirma con la mirada este retorno de Juan Darién al mundo natural y se establecen los marcos de reconocimiento (frames of recognition ${ }^{3}$ ) de los cuerpos humanos y animales en su distinción excluyente, según Judith Butler, estos actúan como "categories, conventions, and norms that prepare or stablish a subject for recognition, that induce a subject of this kind, precede and make possible, the act of recognition itself" (5). En el acto de reconocimiento, la ambigüedad identitaria es proscrita, es marcada como una alteridad dañina al otrora cachorro huérfano.

\section{El ARCHIVO, EL TIGRE Y SUS METÁForAS}

El establecimiento de los marcos de reconocimiento de identidades y diferencias se une a un tronco de relatos latinoamericanos que auscultan su panorama cultural para explicar la raíz de la identidad y los conflictos culturales del continente, según Roberto González Echeverría este tipo de narrativa "se ocupará obsesivamente de ese Otro Interno que puede ser el origen de todo, es decir, el origen violento de la diferencia que distingue América Latina" (148). El gesto de identificar el origen del tigre en la narración de Quiroga establece a Juan Darién como un documento de las operaciones del saber y el poder entretejidos para capturar, perseguir y eliminar la diferencia animal. Estas acciones administran lo sensible y rigen lo visible en la política literaria de la representación que se establece en la trama del relato.

La búsqueda del origen -esa indagatoria por el Otro Interno- en la literatura latinoamericana es el marco general de la escena de la escuela y los latigazos del relato de Horacio Quiroga. El cuento establece las condiciones para el reconocimiento como se ha argumentado hasta ahora con la expulsión del animal del colectivo humano. El narrador del cuento seńala otro elemento para este reconocimiento: "Los chicos y muchos hombres no cuentan lo que ven, sino lo que han leído sobre lo mismo que acaban de ver" (Quiroga 184). De esta manera, la alteridad animal tiene un contenido definido de antemano por un archivo letrado que guía la mirada inquisidora. Los diagramas del saber construyen las disposiciones del ver, la mirada pide ver con una mezcla de deseo y política, "de même que la vue que nous avons des choses à travers les images se trouve conditionné par les vues, c'est-à-dire les jeux du désir et les enjeux politiques de tout ceux qui 'demandent voir', de tous ceux qui suscitent le visible ou font usages des images" (Didi Huberman 71). El inspector sabe qué hacer con una fiera -él guía una pulsión del pueblo por aquello que

\footnotetext{
${ }^{3}$ Concepto en el original (la traducción es mía).

${ }^{4}$ Asimismo, la visión que nosotros tenemos de las cosas a través de las imágenes se encuentra condicionada por las visiones, esto quiere decir, por el juego del deseo y la apuesta política de todos aquellos que "piden ver", de todos aquellos que suscitan lo visible donde hacen uso de las imágenes (la traducción es mía).
} 
demandan ver y perseguir-, él busca expulsar de su interior a los seres de la jungla, aquellos que -en función del saber, la civilización y la cultura- se deben distinguir los humanos. El animal es una metáfora cargada de la violencia depositada en la naturaleza, los habitantes del pueblo se alinean con el orden de esa metáfora.

Esta establece un saber sobre el tigre, lo entiende como un devorador de humanos. Cada concepto se intercambia por otro: animal, fiera, predador. Este trabajo de la metáfora es importante por el uso que hace del lenguaje y las operaciones asociadas con él, "implica una transferencia del significado de una expresión a otra por una semejanza, que lleva a la sustitución de esta por aquella" (Villa 304). En ese orden de la suplantación se intercambian las cosas por su representación, en virtud de un traslado de un dominio a otro.

En oposición a la metáfora, la metonimia se opone a la sustitución y el remplazo en el uso del lenguaje. El tropo asociado con la sinécdoque sintetiza un modo de pensamiento -destacado por el estructuralismo desde Jakobson, pasando por Lacan hasta Deleuze-. Ambas figuras retóricas anudan el pensamiento, el lenguaje y la acción, ambas no son tratadas como "figuras de la imaginación, sino como factores estructurales. Se trata incluso de los factores de la estructura, en el sentido de que expresan dos grados de libertad de desplazamiento, de una serie a la otra y en el interior de la misma serie" (Deleuze 239). En síntesis, la metonimia alineada con el eje del sintagma, el orden horizontal, en sus intercambios por contigüidad dentro de la serie; mientras que la metáfora se inscribe en el paradigma, el orden vertical, por ende, opera en el traslado de una serie a otra.

Los argumentos señalados por Gilles Deleuze, el pasar de una serie a otra, tienen un ejemplo clásico señalado por Levi Strauss en la triada culinaria: lo crudo, lo cocido y lo podrido. Los elementos del triángulo son operaciones de la cultura. Procesar y cocinar son una mediación de los elementos de la naturaleza, las operaciones de la cocción traspasan sus valores desde series horizontales hacía niveles paralelos. Las cadenas de organización interna pueden trasladarse y así establecer lo crudo como lo natural y lo cocido como lo cultural. Asimismo, en el relato quiroguiano, la diferencia entre la humanidad y la animalidad del protagonista traslada lo alimenticio (el devorador de hombres), lo político (la expulsión del animal de la sociedad) y lo ontológico (las diferencias entre humanos y animales). Las tres series están fundamentalmente interconectadas y son la base del sustento de la diferencia entre la naturaleza y la cultura inscrita en un cuadro de sustituciones excluyentes y metáforas.

El tigre está en una serie literaria por su valor metafórico asociado con un animal de palabras, pero, más allá del juego de categorías humanas y animales: ¿Cómo podemos identificar la metáfora del tigre en el canon latinoamericano? ¿Cuál puede ser la sustitución de un tigre por otro? Domingo Faustino Sarmiento usa el apelativo del tigre para designar a Facundo Quiroga en su obra de cuya lectura se desprende la oposición entre la civilización y la barbarie. En esa línea de asociaciones verticales y sustituciones de un signo por otro, de un tigre por otro, se inicia una animadversión felina connotada por aspectos de la especie, de la política y la cultura.

La ficción felina del tigre se asimila a la existencia exterior de un animal exótico y oriental, depositario de la violencia telúrica, preso del hambre y el instinto. Su versión 
más terrible lo describe con un persistente apetito de carne humana, el tigre cebado, cuya invocación se hace en la escuela del relato de Quiroga "—iEs un tigre! ¡Juan Darién nos va a devorar! ¡Muera Juan Darién!” (186). El animal sediento de sangre, predador de los humanos. El trasfondo de esta oposición en los relatos de Quiroga se anima por una comprensión específica de la naturaleza, "dura y combativa. Si el hombre espera, pasivamente, de ella el éxtasis o la sensación abisal del ser, sería devorado por las víboras o por las hormigas gigantes o por lo bichos y los insectos" (Jitrik 96). En ese trasfondo amenazante de la naturaleza como un polo de la devoración, el tigre es una fiera en palabras del pueblo, pero asimismo la adopción del tigre indica una disidencia con ese orden de la metáfora cuyo eje asocia tigre, predador y bestia.

La metáfora del tigre es erigida como una ficción exotizante productora de alteridades, concentra todas las características negativas en el animal en un orden vertical -el eje paradigmático de Jakobson- de suplantaciones. Esta acumulación de rasgos los usa el archivo literario establecido por medio de los saberes de los viajeros del siglo diecinueve, su archivo produce el malentendido de las designaciones de las especies felinas, el tigre exótico y oriental se sobrepone al jaguar americano, volviendo a la escena fundacional relatada por Sarmiento, cabría argumentar con González Echeverría que, al atribuir las cualidades del animal devorador de personas a Facundo Quiroga, "[e]l tigre [...] entra en la "extraña escena” bajo el estandarte de una designación errónea. Obviamente, no se trata de un tigre, sino de una especie de jaguar" (González Echeverría 178). El efecto de la ficción es exótico y atemorizante, ya que una vez "ha probado a un humano, el tigre adquiere predilección especial por estos, una predilección basada en un conocimiento extraordinariamente íntimo, secreto y prohibido de lo humano. "Cebado" significa tener un conocimiento previo que incita al deseo" (178). El propósito de usar esta metáfora es la suplantación, convertir al tigre vuelto niño en un devorador del pueblo, usarlo como una metáfora de un predador exterior, exótico, deseante y sediento de sangre. Esa referencia de la animalidad empuja al niño felino a una alteridad despiadada, contaminante y peligrosa: el tigre. El animal perpetra un golpe al pacto humano establecido en la identidad, ejercido por medio de la palabra y difundido en la escuela con el propósito de promover el poder pastoral, encargado justamente de cuidar las ovejas del rebaño del apetito un animal depredador.

La connotación devoradora de hombres del tigre se alimenta de la ficción caníbal de la alteridad. Si Juan Darién es un ser humano con la posibilidad de devorar a otros humanos se volvería un caníbal, la alteridad por excelencia de la misión colonial y la máquina antropológica. La metáfora de la deglusión promueve la indistinción, la confusión y el borramiento de los límites de la especie en "Juan Darién". Carlos Jáuregui en Canibalia caracteriza el acto caníbal a la luz del uso de esta metáfora en la tradición literaria latinoamericana, según el crítico "El caníbal no respeta las marcas que estabilizan la diferencia; por el contrario, fluye sobre ellas en el acto de comer. Acaso esta liminalidad que se evade-que traspasa, incorpora e indetermina la oposición interior/exterior" (Jáuregui 13). El cuestionamiento del interior y el exterior en Juan Darién convoca lo animal de lo humano y borra su frontera establecida en la lección de la especie inscrita por el poder 
pastoral. Así también las normas alimenticias son metáforas de la integración cultural y la filiación asociadas con la mediación de la naturaleza, y, como lo señala Levi Strauss, este orden está relacionado con la cocina y la sexualidad. Las normas de los tabúes alimenticios y sexuales (regulados por el parentesco) señalan el interior y el exterior de una comunidad, por lo tanto, su ruptura implica la disolución del vínculo social, una vez más, el nińo felino quiebra el orden de la norma por su amenaza de predación y por su vínculo de parentesco.

La existencia criminal del tigre según el poder pastoral implica la deglución de los vínculos políticos, tal como lo describe Michel Foucault en Los anormales, para el crítico francés la amenaza del poder es un pueblo caníbal como bien lo destaca Renan y luego José Enrique Rodó a propósito del Ariel. Por otro lado, el tigre encarna esa posición criminal, solitaria, sigilosa y al acecho, cuya constitución amenaza con romper con la paz social debido a su comportamiento cazador, sus ojos como dos carboncillos acechan desde las matas a la aldea.

\section{LOS TIGRES Y LOS LOBOS}

La relación del animal con el enemigo de la sociedad en el orden vertical de las metáforas ubica al tigre a un lado de la violencia, la deglusión y la barbarie. Él es la violencia contenida y depositada en el enemigo que amenaza la estabilidad del pueblo. La violencia latinoamericana orientalizada es representada por el tigre, mientras que en la filosofía política hobbesiana este lugar lo ocupa el lobo. La ficción del animal dentro de la sociedad es una amenaza potencial, entonces es un peligro preservar a Juan Darién dentro de la aldea.

$\mathrm{Su}$ presencia supone una amenaza en tres niveles, el primero es su bestialidad sospechosa que diluye los márgenes de la humanidad, porque el depredador hace de los humanos una presa fácil. La inclusión del animal amenaza la seguridad pastoral. La bestia traspasa la barrera que escinde la naturaleza y la cultura. El segundo nivel es el lugar de alteridad del animal, la bestia al interior del pueblo representa la violencia de los humanos en condición de naturaleza, ese devenir bestia del hombre, como lo señala Torrano leyendo a Hobbes y Agamben. La expulsión prohíbe el instinto agresivo del estado de naturaleza asociado con el tigre. La visión gregaria del poder pastoral implica que nadie se escinde, nadie debe ser un depredador solitario, por ende, se prohíbe la predación y se niega la condición de lupus homini lupus. Nadie puede ser un devorador de hombres en la aldea. En ningún caso los seres humanos pueden ser presas, la cualidad de la humanidad se basa en su integración en una mismidad, la sociedad se construye con la acción de "subsumer le groupe sous l'autorité du Même ou de l'Un : mêmeté de chacun pour faire un seul tout social, unité de la règle que réunit socialement chacun avec tous" (Didi-Huberman 65).5 Cazar a un hombre es ser una fiera, una aporía ontológica, una avería antropológica, una alteridad en

\footnotetext{
${ }^{5}$ Lo ideal es subsumir el grupo bajo la autoridad de lo mismo o lo uno: la mismidad para hacer un solo todo social, unidad de la regla que reúne a cada uno socialmente con todos (la traducción es mía).
} 
el seno de lo social, una diferencia en medio de la mismidad, ese predador se debe eliminar para salvaguardar la identidad y la integridad social.

Por último, el tercer nivel es la amenaza animal inscrita ambiguamente en la política, puesto que el hombre bestia es clasificado como el enemigo interno: homo homini lupus. Su marginación preserva el orden y la estabilidad con la finalidad de exponer su diferencia. El espectáculo de la tortura tiene por objetivo asesinar al niño felino para que las miradas del pueblo inscriban esta diferencia según un aparato político de la mirada como dice Didi-Huberman.

La constitución animalizada cuasimonstruosa del hombre/lobo, aquí el hombre/ tigre, se sitúa en una posición disruptiva respecto del imperio de la ley. La primera clave de antropologización es la exclusión de la bestia del hombre que "denominamos devenirhombre-del-lobo, la bestia que habita el hombre es puesta al margen; para de este modo presentar al hombre a distancia de la bestialidad" (Torrano "El monstruo" 432). La monstruosidad de ese camino es la reversibilidad de su trayectoria -su tránsito- que incide en una reformulación de la ontología humana no como una ficción estable respecto de la especie. Lo humano es un devenir de lo animal, un retazo de lo viviente vuelto autónomo y distanciado de la animalidad, esa distancia tiene un recorrido y se establece en un ejercicio de un marco de reconocimiento específico, acto que implica un remanente porque "[p] roduction is partial and is, indeed, perpetually haunted by its ontologically uncertain double. Indeed, every normative instance is shadowed by its own failure" (Butler 7). La expulsión de lo animal en lo humano implica lidiar con esa porción parcial, ontológicamente incierta como su falla, delimitada y obliterada reiteradamente por un acto de fuerza estatal en el caso del relato analizado.

El funcionamiento del Estado y la soberanía están basados en una estrategia que limita los flujos, contactos y transformaciones ontológicas. La bestialización del hombre predador, el homo homini lupus, se alimenta de los adherentes del pacto social-como Juan Darién que, en la visión de la gente de la aldea, va a devorar a su pueblo-. Así, el dispositivo que lo persigue promueve su exclusión, aunque lo reconoce para volverlo una alteridad, "el hombre-lobo permite comprender la formación de la ciudad de los hombres a partir de la exclusión-inclusiva del lobo. El hombre-lobo no es una figura de pura exclusión, sino de una inclusión a partir de la exclusión" (Torrano "El monstruo" 438). Esta noción de bisagra biopolítica pone en acción la lógica del poder soberano y el enemigo interno como una dualidad necesaria para activar la soberanía. Esta última funciona internamente como un dispositivo activado para la exclusión. La presencia del hombre-bestia es una amenaza que justifica el ejercicio del poder. La exclusión de la dimensión no humana del hombre, su parte animal, es expulsada por los mecanismos de resguardo de la identidad. Estos dispositivos del poder pastoral en el cuento van a ser la escuela, la mirada del funcionario, la tortura, la palabra del archivo y el uso del tigre como una metáfora peligrosa y feroz.

Juan Darién, humano y animal, viola el ejercicio de la soberanía estatal, el inspector fiscal urge por su muerte, los habitantes del pueblo lo secundan en sus intenciones, ya que su ambigüedad lo hace ser considerado un monstruo. Juan Darién hace peligrar el ejercicio 
de la ley, la proscribe porque "su existencia misma y su forma, no sólo es la violación de las leyes de la sociedad, sino también de las leyes de la naturaleza-. Es, en un doble registro, infracción a las leyes en su misma existencia" (Foucault, Los anormales 61). La máquina antropológica y discursiva se despliega en esta persecución debido a que se ha puesto en entredicho la ontología estática de lo humano por medio de una filiación provocada por una corporalidad transformadora como una versión biopolítica donde lo social se abre a la heterogeneidad de lo viviente. Así "[e]l monstruo es la posibilidad de la metamorfosis, de la transformación, es la potencia de la vida en toda su virtualidad" (Torrano "Ontología" 5). La filiación materna de Juan Darién funciona como una relación corporal humano animal, este pacto pone en crisis la ley del Estado y la ley de las especies: "Es el límite, el punto de derrumbe de la ley" (Foucault 61). Afirma una relación disconforme con el funcionamiento de esa norma y derrumba el muro que circunda la exterioridad natural. La crisis antropológica se funda en la proliferación de alianzas establecidas por filiaciones imprevistas entre humanos y animales.

La adopción de Juan Darién en el inicio del cuento estrena nuevos marcos de reconocimiento y hace un pacto entre dos cuerpos diferentes que se abre hacia una comunidad. La relación filial del tigre y la mujer está basada en el "amor entrañable de su hijo, amor que ella devolvía con todo su corazón" (Quiroga 183). La relación cordial establecida entre ambos violaba el pacto hetero-normativo de la familia patriarcal, rompía el tabú de la filiación, quebraba la asimetría entre humanos y animales y se mantenía en la transformación corporal cuya base es el amor, "el saber amar es poner en círculo las fuerzas pasionales con la actividad de la mente" (Muraro El orden 23). El contacto de sus cuerpos vinculados después de su primer abrazo, cuando el tigre encuentra el arrullo en el seno maternal, promueve una relación contra el poder pastoral ejercida en la selva, este espacio es una "zones de voisinage: umbrales de vecindad, de contigüidad, de "indiscernibilidad" entre cuerpos y entre especies" (Giorgi "La rebelión" 167). La invisibilidad del otro es reemplazada por la encarnación de un vínculo transformador de las formas de cómo se distribuye lo sensible, "el animal-vecino es un cuerpo que suspende un orden dominante de individuaciones" (Giorgi "La rebelión” 168). Las consecuencias de la mediación corporal en la alianza humano animal entre la mujer y Juan Darién cuestionan el discurso de la especie.

El poder pastoral clasifica y rige los cuerpos, captura sus cualidades y establece la forma de nombrarlos. Por el contrario, la alianza humano animal reorganiza lo visible, lo expresable y las formas de su distribución, el cuerpo de Juan Darién en alianza con su madre borronea los límites de la exclusión de lo natural en lo humano. ${ }^{6} \mathrm{El}$ proyecto de Horacio Quiroga según Gunnels se basa en la investigación sobre el límite de lo animal humano y la promoción de los derechos de los animales en función de una hibridación, según la autora, la propuesta del cuento,

\footnotetext{
${ }^{6}$ Uso la palabra borronea para aludir al título del artículo de Bridgette W. Gunnels, "Blurring boundaries".
} 
challenges anthropocentrism by giving life to his animal protagonists and envisioning them as not only sentient members of our world but acting of their own volition and exhibiting a full range of emotions, thus eroding the neat categories and divisions that previously have formed boundaries (357).

Los límites excluyentes entre las especies se cruzan por medio de la hibridación, el contacto, el amor entre los cuerpos, el arrullo y la acogida del felino promueve una acción de alianza basada en el arrullo, en el calor y el amor de la madre con su hijo adoptivo.

\section{ANimales Comunes}

La indistinción entre el humano y el animal también se tensiona por otro camino en el cuento. La ambigüedad de la identidad en el niño felino deriva de su inadecuación con las reglas de filiación del parentesco de la antropología, estas son puestas en juego debido al vínculo entre las especies en su alianza más allá de lo humano. Su relación no pasa por la sexualidad ni por la especie, su parentesco rompe con esta alianza antropológica. El vínculo central de la narración propone una crisis de la distinción entre la naturaleza y la cultura. En este extraño parentesco se usa el cuerpo como un puente entre especies diferentes, hay una alianza que va más allá y permite,

otra comprensión de lo que es un cuerpo, lo que puede y, sobre todo, de lo que pasa entre cuerpos: de lo que se inventa entre ellos, el lazo común que surge en la inmanencia de su relación, el espacio común que se crea en los agenciamientos entre cuerpos (Giorgi Formas 42).

La adopción de Juan Darién por la mujer en el inicio de la acción implica que la exclusión animal de lo humano se invierte y se transforma en una posibilidad de sostener un vínculo que reorienta lo político.

La mujer madre y el felino se unen en su dimensión corporal que destituye las formas fijas de administración del bios en la polis, ejecutado por las exclusiones biopolíticas en la que el recorte de lo viviente humano deja en el trasfondo la vida animal sin forma. La cosmopolítica -fundada en la heterogeneidad de lo viviente- "esa cosmopolítica de la que habla Viveiros de Castro en la que lo social no se reduce nunca del todo a lo exclusivamente humano" (Giorgi 42), opone una capacidad de resistencia a la máquina de exclusión antropogénica y transforma las exclusiones en que lo animal y natural son lo dado -o un fondo no marcado por una mediación- mientras que lo humano y cultural son la figura, es decir lo marcado y organizado, mediado por el lenguaje y por la política.

La cosmopolítica de lo viviente redefine las alianzas e integra lo animal en lo humano, hace una convivencia amorosa entre la madre y el animal, su relación de amor ha sido establecida por un vínculo intenso, su reunión corporal tiene un sello amoroso: 
"el tigrecito, al sentir el calor del pecho, buscó postura cómoda, runruneó tranquilo y se durmió con la garganta adherida al seno maternal” (Quiroga 182). La transformación de Juan Darién tiene una reversibilidad, puesto que la impugnación de ese vínculo por medio de la protesta de otra madre restaura el orden de las identidades quitándole la apariencia humana al felino. Juan Darién puede ser un niño siempre y cuando otra madre no reclame contra su inclusión al interior del pueblo selvático.

El cuerpo de Juan Darién es una zona de contacto, una frontera porosa, una zona de vecindad en conflicto, una convivencia no estatal basada en la proximidad corporal sellada en el contacto de dos cuerpos de especies distintas que en su mediación establecen una relación basada en el tacto metonímico ajeno al pacto metafórico, en este contexto son acertadas las reflexiones de Georges Didi Huberman sobre el tacto, sobre tocar, sobre la destreza (doigtesse) del contacto, "Le tact réunit en un même geste le 'physique' et le 'moral', comme on dit. Question de 'doigté, de délicatesse. C'est la vertu pour ne pas blesser autrui et l'atteindre cependant" (82). ' La alianza de los dos cuerpos entrelazados cruza las fronteras de lo viviente y se construye como otra mediación, delicada y sin daño, una alianza de los cuerpos, una alianza del afecto, una transformación de las filiaciones y las genealogías, un contagio que salta la linealidad y homogeneidad de las cadenas significantes de los cuerpos.

El contacto inicial entre la madre adoptiva y el felino huérfano establece una mediación cordial y corporal, la madre "sin pensar bien en lo que hacía llevó el cachorrito a su seno y lo rodeo con sus grandes manos" (181). Esa madre acoge en su seno y amamanta al tigre, "El cachorro, suave y cariñoso -[...] jugaba con ella sobre su pecho-, era ahora su propio hijo" (182). Su mediación, el parentesco entre una madre humana e hijo animal es una unión de lo común, un salto entre las especies, una alianza filial del amor de esa madre por su hijo adoptivo, su vínculo se establece en el contacto y su delicadeza - doigtessepodríamos señalar junto con Georges Didi-Huberman.

La relación de la madre y su hijo adoptado se opone al pacto social del pueblo, por el contrario, la madre y Juan Darién son una comunidad, aunque no son iguales ni homólogos, eso no importa para que sus cuerpos se reconozcan en su diferencia. En oposición al pueblo la madre al ver el cuerpo del cachorro de tigre no ve una fiera. Su reconocimiento se opone al orden del discurso basado en las metáforas establecido por la escuela, el poder pastoral y la tradición literaria, cuyas bases están en "la elaboración simbólica [que] pasa por definir las cosas, duplicar el mundo en una representación” (Muraro Maglia 4-5). Ese mundo de la representación entiende que todas las fieras son enemigos de los humanos, ergo, Juan Darién como fiera es tratado como un enemigo interno de la especie.

En oposición a la sustitución por representaciones asociado con el orden de la metáfora, en el contacto y la metonimia hay un orden simbólico disidente establecido en la proximidad o contigüidad, así ocurre según Luisa Muraro cuando "las cosas son significadas a través de lo que las acompaña en las secuencias naturales o en el uso humano" (5). El uso

\footnotetext{
${ }^{7}$ El tacto reúne en un mismo gesto lo "físico" y lo "moral". La cuestión de la "destreza", de la delicadeza. Esto es la virtud para no herir al otro y alcanzarlo de todas maneras (la traducción es mía).
} 
metonímico del lenguaje basado en la proximidad y el contacto material habilita el cariño de la madre por Juan Darién. El afecto humano materno por un felino lo hace a este un niño.

Aunque la exclusión entre las especies prioriza la metáfora como un orden abstracto de las identificaciones, mediadas por el lenguaje y sostenidas por una autoridad que confía en "palabras en lugar de las cosas, el significado figurado en lugar del literal, el universal en lugar del particular" (Muraro Maglia 7). Los mecanismos de producción del pensamiento y el lenguaje basados en el sentido abstracto y metafórico son un fundamento para creer que tigre, fiera y enemigo se conjugan en la misma cadena de significado.

La inclusión del niño felino está prohibida por su proximidad con la selva, la naturaleza y la vida fuera de los parámetros de lo humano. Su exclusión no radica en una falta de mediación, pues la hay, su inclusión es producto del amor de su madre adoptiva que lo acoge inicialmente en su seno. Esa relación corporal es un vínculo entre dos seres vivientes que, aunque no idénticos en tanto especie, se asimilan en una política de lo natural, así "Lo animal, más que una figuración estable que se opondría a lo humano, ilumina una materialidad corporal, y un campo de intensidades y fuerzas que no se terminan de codificar o de capturar bajo el signo de un yo, de un sujeto, de una conciencia individual" (Giorgi "Ficción" 6). El animal trae consigo esa energía, el vínculo basado en la unión filial de dos cuerpos que expropian a la palabra su capacidad mediadora. Este vínculo pactado en el seno materno es efectuado fuera de la palabra y la lógica, la madre recoge al cachorro sin pensar bien (sic), por ende, fractura el pensamiento basado en la representación de las metáforas.

Esta alianza pone en suspenso el uso de la lengua como garante de la mediación social. El uso del sentido metafórico de la palabra es una manera de ejercer la abstracción, mientras la relación entre cuerpos redefine las fronteras de lo viviente y las alianzas de lo común. La fuerza de esta relación reside en la redefinición de los marcos de reconocimiento como dice Butler, que son intervenidos y puestos más allá de los acuerdos establecidos por medio de la palabra en tanto abstracción y trascendencia. La impugnación de esa lógica, en cambio, valora la intensidad de los cuerpos y los afectos que inauguran otros vínculos donde lo social no se reduce a lo humano. La relación maternal designada en el contacto y la proximidad hacen del tigre un humano. Su salida del mundo natural y su ingreso al mundo cultural no pasa por la palabra.

Los términos de esta alianza modifican la definición de identidad para estos sujetos, su inclinación hacia la animalidad y corporalidad redefinen la forma clásica de concebir la ontología como una sustancia libre de contaminación y contacto, por el contrario, una proposición de la filiación humano animal plantea,

una ontología relacional. Esto significa que los entes no tienen una existencia separada, estos se van constituyendo en sus múltiples interacciones. Por lo cual esta ontología es socio-histórica en el sentido que todas las entidades son lo que son con relación a otras entidades -tanto humanas como no humanas- (Torrano Ontología 3). 
De esta manera, la transformación tigre-niño fruto de la filiación materna implica una forma nueva de vinculación humano animal como un tránsito posible hacia una ontología relacional. Esta relación desestabiliza el régimen de las identidades, la exclusión entre naturaleza y cultura y la diferencia entre humano y animal, también viola el conjunto de leyes sociales, naturales e históricas que rigen estas interacciones.

Las consecuencias de esta alianza van más allá. En la objetivación de la naturaleza por parte de la lógica capitalista, la separación entre sujeto y objeto es un ejercicio primordial para establecer las relaciones de dominación. En el caso de la transformación de Juan Darién esa escisión no es clara, porque existe un contacto que desdibuja la frontera entre la naturaleza y la cultura que inaugura un devenir y presenta un disenso con el ejercicio de la dominación y se presenta como bloqueo al avance del capitalismo y el Estado. De hecho, como indica Andermann, "[l]a continuidad de lo viviente es el gran obstáculo con que se encuentra el avance capitalista, y contra la que vuelca su discurso de la especie en función de poder introducir un quiebre, una distancia, entre sociedad y naturaleza" (6). La proximidad se abre hacia una ontología relacional, una proximidad intensa del cuerpo que genera un devenir.

Esta transformación afecta los mecanismos de definición de la especie y su pertenencia a un registro cerrado de frontera con lo viviente. El ejercicio de imponer categorías se satura ante la imposibilidad de no poder clasificar e identificar. La máquina estatal irrumpe con violencia para marcar con el látigo y el fuego las rayas de tigre en el cuerpo prisionero de Juan Darién. El despliegue de la violencia soberana se aplica por medio de su inscripción violenta en la gramática del poder. La raya, la marca, el látigo y el fuego son señales explícitas de la fragmentación de la continuidad de lo viviente bajo la sentencia excluyente que recorta lo humano de lo animal, lo cultural de lo natural, que termina en la asociación exclusiva de lo político con lo estatal. La escuela y el discurso letrado son el escenario de ese recorte, el acto de excluir y separar a Juan Darién de los estudiantes. Lo lastiman para convertirlo nuevamente en un tigre bajo el sojuzgamiento de la mirada del funcionario estatal, quien identifica al niño felino con el tigre: devorador de hombres y agitador del orden.

Esa acumulación de significados adquiridos, paralelos al tigre de la llanura, coinciden con esa mirada del archivo sobre el animal exótico. Ese animal oriental, exógeno, tigre cebado, que busca la eliminación de los vínculos sociales, devorador de hombres. La metamorfosis de Juan Darién es la presentación de un flujo entre los cuerpos humanos y animales, la transformación, la disrupción de la ontología y la creación de un régimen de filiación que se opone a la subjetivación que promueve el Estado basada en la objetivación de la continuidad de la vida para el dominio capitalista, opuesta a la familia felino maternal del cuento. El arrullo, el amor, el seno materno son la mediación corporal facilitadora del encuentro de la madre con el cachorro huérfano. El orden de estas relaciones se basa en el contacto y en la alteración de los marcos de reconocimiento del otro. Frente a un orden metafórico y vertical donde los significados del tigre son aterradores, este cuento, por el contrario, muestra cómo el cachorro huérfano es acogido por una mujer sola en la selva. 


\section{Conclusión}

La adopción del tigre pone en crisis los marcos de reconocimiento y las alianzas en el poblado de la selva en "Juan Darién" de Horacio Quiroga. Los argumentos desplegados a favor de la filiación entre el tigre huérfano y la madre se oponen al poder pastoral que ocupa la escuela en la lectura. La unión de estos dos cuerpos muestra la crisis de los argumentos civilizatorios y corre el tupido velo de la convivencia entre saber, poder y violencia con el que Quiroga inaugura un "disenso literario [que] opera sobre los cambios de escala y de naturaleza de las individualidades" (Rancière 72). La literatura opera en los malentendidos y en las bifurcaciones, la transformación de lo sensible del arte recubre de nuevos significados y textualidades los usos del cuerpo. Este uso crítico redefine la naturaleza, lo humano y lo animal junto con las posibilidades de nuevas filiaciones políticas fuera del campo de acción de lo estatal en dimensiones porosas.

La alianza de los cuerpos opone un uso metonímico del lenguaje basado en el contacto y la proximidad en contra de un uso metafórico articulado en las suplantaciones que consideran al animal como una fiera que debe ser expulsada del seno de la sociedad. El poder pastoral establece una equivalencia entre animal, bestia, devorador de hombres, tigre cebado y enemigo interno y para combatirlos utiliza mecanismos coercitivos que instalan un orden discursivo, epistémico, y ontológico.

En contraposición, la alianza humano animal es un tejido escindido de aquellos mecanismos de subordinación y promueve la intensidad de las relaciones corporales, la desarticulación de las fronteras que asignan un sujeto a un cuerpo determinado y a una especie. Esta narración muestra una relación de amor y acogida que deviene en la metamorfosis de Juan Darién de animal a humano. Esta alianza hecha en el contacto y unión de dos cuerpos diferentes, el de la madre y el felino huérfano, establece un vínculo hecho por el contacto, por la contigüidad, que establece una relación amorosa de comunión de la diversidad de lo viviente y desafía los presupuestos de la voluntad de dominio del sujeto por sobre el cuerpo. En este caso, el cuerpo tiene una potencia virtual, los sujetos se transforman y ya no pertenecen a una identidad excluyente de lo animal en lo humano. A pesar de todo, el imperio de los signos se restablece con la orden de capturar a Juan Darién para marcar con fuego su cuerpo para develar las rayas de su cuerpo animal. La insistencia de esta inscripción metafórica de la bestia, el animal y el enemigo reinstala un régimen de identificaciones basado en el uso del archivo, la letra y la mirada.

\section{Obras citadas}

Abreu Mendoza, Carlos. 2014. "Horacio Quiroga, Writer on the Limits", A Contracorriente: Revista de historia social y literatura de América Latina 11.2: 302-22.

Andermann, Jens. 2017. "Tesis sobre la metamorfosis". Boletín, Centro de Estudios de Teoría y Critica Literaria. CELAR, Centro de Estudios de Literatura Argentina. http:// www.celarg.org/int/arch_publi/andermann_animalidad.pdf 
Ayala, Matías. 2020. Poéticas de lo viviente, lo animal y lo impersonal. Santiago: Metales Pesados.

Butler, Judith. 2009. Frames of war. Nueva York/London: Verso.

Deleuze, Gilles. 2002. ¿Cómo reconocer el estructuralismo? La isla desierta y otros textos. Textos y entrevistas (1953-1974). Valencia: Pre-textos.

Didi-Huberman, Georges. 2012. Peuples exposés, peuples figurantes. L'oeil de l'histoire. Normandie: Les Éditions de Minuit.

Duarte, José. 2006. "Horacio Quiroga como escritor de frontera", Hipertexto, n. 1: 116-20. Fernández Retamar, Roberto. 2002. Calibán. Puerto Rico: Ediciones Callejón.

Espósito, Roberto. 2009. Comunidad, inmunidad y biopolitica. España: Herder.

Foucault, Michel. 2011. Los anormales. Buenos Aires: Fondo de Cultura Económica. . 1996. "Omnes et singulatim: hacia una crítica de la razón política". En Michel Foucault, Los hombres infames. La Plata: Editorial Altamira,

Giorgi, Gabriel. 2011. "La rebelión de los animales: zoopolíticas sudamericanas". Aletria. Revista de Estudos de Literatura, 11.3. . 2014. Formas comunes. Animalidad, cultura, biopolitica. Buenos Aires: Eterna Cadencia.

. 2012. "Ficción de la especie". Caja Muda, n. 4. https://www.facebook.com/revistacajamuda/

González Echeverría, Roberto. 2011. "El mundo perdido redescubierto: Facundo de Sarmiento y Os sertóes de Euclides da Cunha. Mito y Archivo. Una teoría de la narrativa latinoamericana. Ciudad de México: Fondo de Cultura Económica.

Gonçalvez Duarte, Ricardo José. 2017. “Corpos híbridos e florestas em 'Juan Darién’ e Mal dos trópicos”. Revell, 3.17: 350-69.

Gunnels, Bridgette W. 2006. "Blurring Boundaries between Animal and Human: 'animalhuman' rights in 'Juan Darién' by Horacio Quiroga”, Romance Notes, 46.3: 349-58.

Jáuregui, Carlos. 2008. Canibalia. Canibalismo, calibanismo, antropofagia culturaly consumo en América Latina. Madrid: Iberoamericana-Veuvert.

Jitrik, Noé. 1959. Horacio Quiroga. Una obra de experiencia y riesgo. Buenos Aires: Ediciones culturales argentinas,

Kafka, Franz. "La colonia penitenciaria”. Biblioteca Digital Ciudad Seva. http://www.ciudadseva.com/textos/cuentos/euro/kafka/la_colonia_penitenciaria.htm.

Muraro, Luisa. 1981. Maglia e Uncinetto. Racconto linguistico-politico sulla inimicizia tra metafora e metonimia. [Dos agujas o Crochette. Relato lingüístico-político sobre la enemistad entre metáfora y metonimia] Traducido por Elsa Drucaroff. Milán: Feltrinelli. . 1994. El orden simbólico de la madre. Madrid: Edición Horas y horas.

Quiroga, Horacio. 2004. “Juan Darién”. Cuentos. Caracas: Biblioteca Ayacucho.

Rancière, Jacques. 2011. Política de la literatura. Buenos Aires: Libros del Zorzal.

Torrano, Andrea. 2009. "Ontología de la monstruosidad: el cyborg y el monstruo biopolítico" en VI Encuentro interdisciplinario de las Ciencias Sociales y Humanas. Córdoba Universidad Nacional de Córdoba. 
ESTUDIOS FILOLÓGICOS

. 2013. "El monstruo en la política. Defender la sociedad del hombre lobo". En: Contemporãnea. Revista de Sociología da UFSCAR, 3.2.

Villa, María Eugenia. 2018. "Las metáforas en la lingüística. Análisis de algunas conceptualizaciones metafóricas de los fenómenos lingüísticos", Círculo de Lingüistica Aplicada a la Comunicación, 73: 303-14.

Villamizar, Gina. 2020. "Fractura y resistencia en algunos cuentos misioneros de Horacio Quiroga”, Revista Chilena de Literatura, 101: 427-42. 